\title{
Eğitimde Kullanılan Erken Uyarı Sistemleri Konusunda Yapılmış Çalışmaların İncelenmesi ${ }^{1}$
}

\begin{abstract}
Abdullatif $\mathrm{KABAN}^{2}$ ve Ömer BİLEN ${ }^{3}$
$\ddot{O} z$

Veri madenciliği ve yapay zekâ teknolojilerinin ilerlemesiyle öğrencilerin öğretim yönetim sistemleri üzerindeki hareketlerine bakarak geleceğe yönelik davranışları tahmin edilebilir hale gelmiştir. Özellikle riskli öğrencilerin önceden tespit edilerek uyarı vermesi mantığına dayanan erken uyarı sistemleri geliştirilerek uzaktan eğitim veren kurumlara bilgi sağlanmaktadır. Çalışmamızın amacı, eğitimde kullanılan erken uyarı sistemleri üzerine yapılan çalışmaların yayın özellikleri ve veri madenciliğine dayalı analiz yöntemi özellikleri açısından incelenerek mevcut durumun ortaya çıkarılmasıdır. Bu amaç doğrultusunda Google Akademik veri tabanından elde edilen veriler içerik analizi yöntemi ile incelenmiş ve elde edilen sonuçlar frekans tabloları halinde sunulmuştur. Erken Uyarı Sistemleri üzerine yapılan çalışmalar incelendiğinde, bu başlıktaki çalışmalara 2014 yilından sonra başlandığı ve 2018 yllında konu ile ilgili çalışma sayısının arttığı görülmüştür. Bu çalışmaların çoğunlukla ABD'de yapıldığı, makale ve bildiri türünde olduğu ve nicel yöntemlerin tercih edildiği tespit edilmiştir. Yapılan deneysel çalışmalarda verilerin, öğrenme yönetim sisteminden alınan sistem kayıtlarından toplandığı ve verilerin çeşitli veri madenciliği teknikleri kullanılarak analiz edildiği sonucuna varılmıştır. Erken uyarı sistemleri konusunda uygulanabilirliği kanıtlanmış bir modelin henüz geliştirilememiş olması bu çalışmadan elde edilen önemli sonuçlardan biri olarak değerlendirilebilir.
\end{abstract}

Anahtar Kelimeler: Erken Uyar1 Sistemleri, Öğrenme Yönetim Sistemi, Öğrenme Analitkleri, Veri Madenciliği

\section{Review of Studies on Early Warning Systems Used in Education}

\begin{abstract}
The development of data mining and artificial intelligence technologies has led to the fact that the future behavior of students has become predictable when looking at their actions in learning management systems. In particular, early warning systems based on the logic of identify at-risk students and give warnings to them are developed and provide information to distance education institutions. This study aims to examine studies of early warning systems used in education in terms of publication characteristics and data mining analysis methods, as well as to identify the current situation. For this purpose, the data obtained from the Google Scholar database was examined by the content analysis method and the results were presented in frequency tables. When the studies on Early Warning Systems were examined, it was seen that the studies on this topic started after 2014 and the number of studies related to the subject increased in 2018. It was found that these studies were mainly conducted in the United States, represented by articles and conference reports, and the preference was given to quantitative methods. Pilot studies concluded that data was collected from system records taken from a learning management system and that the data was analyzed using a variety of data mining techniques. It can be said that a model that has proven applicability in early warning systems has not been developed yet and this is one of the important results obtained from this study.
\end{abstract}

Key Words: Early Warning Systems, Learning Management System, Learning Analytics, Data Mining

\section{Atıf İçin / Please Cite As:}

Kaban, A. ve Bilen, Ö. (2021). Eğitimde kullanılan erken uyarı sistemleri konusunda yapıllmış çalışmaların incelenmesi. Manas Sosyal Araştrrmalar Dergisi, 10(2), 788-797.

\footnotetext{
${ }^{1}$ Bu çalşsma 13. Uluslararası Bilgisayar ve Öğretim Teknolojileri Sempozyumu ICITS 2019’da sunulan bildiriden türetilmiştir.

2 Dr. Öğr. Üyesi - Bayburt Üniversitesi Bayburt Eğitim Fakültesi, abdullatif.kaban@gmail.com

ORCID: 0000-0003-4465-3145

${ }^{3}$ Dr. Öğr. Üyesi - Atatürk Üniversitesi Oltu Beşeri ve Sosyal Bilimler Fakültesi, omerbilen76@gmail.com

(iD) ORCID: 0000-0001-7288-7606
} 


\section{Giriş}

Erken Uyarı Sistemleri, eğitimciler tarafindan öğrencinin ilerlemesini izlemek ve bir dersten başarısız olma ya da bir ders veya programdan çıkma riski altındaki öğrencileri tespit etmek için kullanılan araçlardan biridir (Jokhan, Sharma ve Singh, 2018, s. 3). Günümüzde belli algoritmalar kullanılarak bu işlemler bilgisayarlara yaptırlsa da 'riski önceden tahmin etme ve önlem alma' fikri dünyada çeşitli alanlarda 80-90 yil öncesine dayanmakta, ülkemizde ise 1970'lerden sonra ilgi görmeye başladığ1 görülmektedir (Sezer, 1994). Risk altındaki öğrencilerin tahmin edilebilmesi için önceden sistem içerisinde sergilediği bazı davranışların ardından başarısız olmuş veya programı terk etmiş öğrencilerin verilerine ihtiyaç duyulmaktadır. Bu verileri kullanarak eğitilen yapay zekâ temelli sistemler geliştirilerek ileriye dönük tahminlerde bulunmak mümkündür (Kotsiantis, 2012, s. 340). Uzaktan eğitimin çevrimiçi ortamlar kullanılarak yürütülmesinin yaygınlaşması ile öğrenci davranışları öğrenme yönetim sistemleri tarafından kaydedilmekte ve bu veriler kullanılarak Erken Uyarı Sistemleri geliştirilebilmektedir (Macfadyen ve Dawson, 2010, s. 589).

Bir öğrencinin risk altında olduğu tespit edildiğinde, öğrencinin ekranına bir işaret konularak, e-posta veya cep telefonlarına gönderilen kısa mesaj yoluyla uyarılarda bulunularak veya öğrencinin bir akademik danışmana yönlendirilmesi sağlanarak çeşitli önlemler alınabilir (Howard, Meehan ve Parnell, 2018, s. 67). Öğrencinin ekranına konulabilecek işaretler ile ilgili Purdue Üniversitesinde tanıtılan, öğrencilerin çevrimiçi ders ara yüzünde trafik ışı̆̆ı rengine dayalı olarak derslerinde başarılı olup olmadıklarını görebilecekleri "ders sinyalleri" veya "trafik 1şığ sistemi" adı verilen bir uygulama örnek olarak verilebilir (Sclater, Peasgood ve Mullan, 2016, p. 26). Bu sistemde farklı risk durumunu ifade etmek için farklı renklerde 1ş1k kullanılmaktadır.

Literatür incelendiğinde, erken uyarı sistemleri üzerine yapılan çalışmalarda elde edilen veriler üzerinde yapılan analizlerde genellikle öğrenme yönetim sisteminden alınan sistem kayıtları kullanılmış ve birçoğunda bu verilere öğrenci bilgi sistemindeki demografik veriler de eklenmiştir. Öğrenme yönetim sistemlerindeki veriler kullanılarak geliştirilen erken uyarı sistemlerinde çoğunlukla aşağıdaki yöntemlere rastlanmaktadır:

- Rastgele Orman Modeli (Elbadrawy vd., 2016; He, Levine, Bohonak, Fan ve Stronach, 2018; Hill, Fulcher, Sie ve de Laat, 2018; Samson, Czarnik ve Gross, 2017; Sandoval, Gonzalez, Alarcon, Pichara ve Montenegro, 2018)

- Lojistik Regresyon Modeli (Arnold, 2017; Hill vd., 2018; Hussain, Zhu, Zhang, Abidi ve Ali, 2018; Waddington, Nam, Lonn ve Teasley, 2016)

- Kümeleme Analizi (Brown, DeMonbrun ve Teasley, 2018; Hung vd., 2017; Stapel, Zheng ve Pinkwart, 2016)

- Destek Vektör Makineleri (Dewan, Lin, Wen ve Kinshuk, 2015, Hussain vd., 2018; Marbouti, Diefes-Dux ve Madhavan, 2016;)

- K-En Yakın Komşu Analizi (Dewan vd., 2015; Marbouti, Diefes-Dux ve Madhavan, 2015; Marbouti vd., 2016)

Ülkemizde Erken Uyarı Sistemleri üzerine tarım, sağlık ve mühendislik gibi çeşitli alanlarda çalışmalar yürütülmesine rağmen, yapılan literatür taramasında riskli öğrencilerin tespit edilmesine yönelik Erken Uyarı Sistemleri geliştirildiği veya test edildiği akademik çalışmalara sadece 2019 yllında rastlanmaktadır (Akçapinar, Altun ve Aşkar, 2019; Akçapınar, Hasnine, Majumdar, Flanagan ve Ogata, 2019). Bu çalışmada Erken Uyarı Sistemleri üzerine yapılan çalışmaların incelenerek mevcut durumun ortaya konulması amaçlanmışır. Bu amaç doğrultusunda aşağıdaki sorulara cevap aranmaktadır:

1. Erken Uyarı Sistemleri üzerine yapılan çalışmaların yıllara göre dağılımları nasıldır?

2. Erken Uyarı Sistemleri üzerine yapılan çalışmaların ülkelere göre dağılımları nasıldır?

3. Erken Uyarı Sistemleri üzerine yapılan çalışmaların türlerine göre dağılımları nasıldır?

4. Erken Uyarı Sistemleri üzerine yapılan çalışmaların yöntemlerine göre dağılımları nasıldır?

5. Erken Uyarı Sistemleri üzerine yapılan deneysel çalışmalarda hangi analiz yöntemleri kullanılmıştır?

6. Erken Uyarı Sistemleri üzerine yapılan deneysel çalışmalarda kullanılan veriler hangi ortamlardan alınmıştır? 
7. Erken Uyarı Sistemleri üzerine yapılan deneysel çalışmalarda yapılan analizler için ne tür veriler kullanılmiştır?

\section{Yöntem}

Erken Uyarı Sistemleri konusunda yapılmış çalışmalarının incelendiği bu çalışmada nitel araştırma yöntemlerinden biri olan doküman incelemesi yöntemi kullanılmıştır. Nitel araştırmalarda doküman incelemesi tek başına bir veri toplama tekniği olarak kullanılabilen, araştırılması amaçlanan fenomen veya olaylar hakkında bilgiler içeren belgelerin analizini kapsayan bir yöntemdir (Yıldırım ve Şimşek, 2005, s. 187).

\section{Verilerin Toplanmas1}

Erken Uyarı Sistemleri üzerine yapılan çalışmaların yapıldı̆̆ı yıl, yapıldı̆̆ı ülke, yayın türü, araştırma yöntemi, çalışmalarda kullanılan analiz yöntemi, analizlerde kullanılan verilerin alındığı ortam ve kullanılan veri türü açısından incelenerek mevcut durumun ortaya çıkarılması amacıyla Google Akademik arama motoru kullanılmıştır. Google Akademik, bilgisayar tabanlı literatür taraması yapmak amacıyla kullanılan, normal arama motorundan farklı olarak sadece akademik dokümanlara ulaşmayı mümkün kılan bir internet arama motorudur (DeGraff, DeGraff ve Romesburg, 2013, s. 44). Bu arama motorunun aramaya ERIC, Web of Science vb. veri tabanlarını dâhil etmesi nedeniyle bu veri tabanlarını ayrıca taramaya gerek duyulmamıstır. Arama yaparken “erken uyarı sistemleri” anahtar kelimeleri birlikte kullanılmıştır.

Google Akademik arama motorundan çok sayıda kayda ulaşılması eğitim ile ilgili çalışmaları ayıklamayı zorlaştırmıştır. Bu yüzden Google Akademik arama motorunda Türkçe ve İngilizce alternatifleri ile "erken uyarı sistemleri" ve "lms" anahtar kelimeleri birlikte kullanılarak arama kapsamı sınırlandırılmıs, bu sayede uzaktan eğitim ile ilgili olanların "lms" anahtarı ile filtrelenmesi sağlanarak ilgili çalışmalara ulaşılmaya çalışılmıştır.

Google Akademik arama motorunda yapılan arama sonucu 512 kayda ulaşılmıstır. Bu kayıtlar sırayla 2019 yılından başlayarak geriye doğru gidilerek yıl bazında incelenmeye alınmıştır. İncelenen kayıtlar içerisinde konusu eğitim ile ilgili olmayanlar ve eğitimle ilgili olsa da diğer yapay zekâ veya genel anlamda öğrenme analitikleri gibi veri madenciliği konularını içeren çalışmalar kapsam dışında bırakılmışlardır. Burada sadece Erken Uyarı Sistemlerinden kuramsal olarak bahseden veya bu sistemin eğitim ortamlarında kullanımına yönelik deneysel çalışma yapan araştırmalar incelenmiştir. Konu dışı bırakılan çalışmalardan sonra kalan 63 çalışma incelenmiş ve araştırma sorularına yanıt aranmıştır.

Bu çalışma yürütülürken 2020 yılı başlarında bulunulduğundan çalışmaya 2019 yılından başlayarak geriye doğru tarama yapılmıştır. Yapılan tarama sonucu ulaşılan çalışmalardan 512 tanesi incelenmiş, 2013 ve 2012 yıllarında elde edilen çalışmalar içerisinde kapsama giren çalışmaya rastlanmadığından ve konunun da güncel olduğu göz önünde bulundurulduğunda inceleme burada noktalanarak daha önceki yıllarda konu ile ilgili çalışma yapılmadığı kanaatine varılmıştır. Konuyla ilgili taranan çalışmalara ait bilgiler Tablo 1'de verilmektedir.

Tablo 1. Google Akademike Arama Motorundan Elde Edilen Calışmalarn Yullara ve Kapsama Göre Dağglımlar

\begin{tabular}{lccc}
\hline Y11 & Incelenen & Kapsam Diş1 & Toplam \\
\hline 2012 & 0 & 28 & 28 \\
2013 & 0 & 29 & 29 \\
2014 & 2 & 38 & 40 \\
2015 & 8 & 37 & 45 \\
2016 & 7 & 68 & 75 \\
2017 & 7 & 78 & 85 \\
2018 & 13 & 67 & 80 \\
2019 & 26 & 104 & 130 \\
\hline Toplam & $\mathbf{6 3}$ & $\mathbf{4 4 9}$ & $\mathbf{5 1 2}$ \\
\hline
\end{tabular}

\section{Verilerin Analizi}

Google Akademik arama motoru kullanılarak elde edilen Erken Uyarı Sistemleri konusunda yapılmış çalışmaların incelendiği bu araştırmada elde edilen dokümanlar içerik analizi yöntemiyle analiz edilmiştir. Cohen, Manion ve Morrison (2007, s. 475), içerik analizinin; metinlerin düzenlenmesi, sınıflandırılması, karşılaştırılması ve metinlerden teorik sonuçlar çıkarılmasından oluşan bir araştırma tekniği olduğunu 
vurgulamışlardır. Bu çalışmada içerik analizi, bu yönlerinin yanı sıra birbirlerine benzeyen verileri belirli kavramlar ve temalar çerçevesinde bir araya getirerek okuyucunun anlayacağı biçime dönüştürmesi nedeniyle tercih edilmiştir (Büyüköztürk, Kılıç Çakmak, Akgün, Karadeniz ve Demirel, 2009, s. 263).

\section{Bulgular}

Erken Uyarı Sistemleri konusunda daha önce yapılan çalışmaların incelendiği bu araştırmada, ulaşılan toplam 63 doküman incelenmiş ve elde edilen bulgular araştırma sorularına göre aşağıda sunulmuştur.

\section{Erken Uyarı Sistemleri Üzerine Yapılan Çalışmaların Yııllara Göre Dağılımları}

Farklı alanlarda Erken Uyarı Sistemleri üzerine çokça yayın yapılmasına rağmen eğitimle ilgili Erken Uyarı Sistemleri uygulamalarının 2014 yılı itibarıyla görülmeye başlandığı tespit edilmiştir. Hata! Başvuru kaynağ1 bulunamadı.'de verilen sayılara bakıldığında 2015, 2016 ve 2017 yillarında Erken Uyarı Sistemleriyle ilgili 7-8 çalışma yapılmasına rağmen, 2018 ve 2019 yıllarında neredeyse bir önceki yıllarda yapılan çalışma sayısının iki katına çıktığı görülmektedir.

\section{Erken Uyarı Sistemleri Üzerine Yapılan Çalışmaların Ülkelere Göre Dağılımları}

Google Akademik arama motoru ile yapılan tarama sonucunda elde edilen çalışmaların yapıldıkları ülkelere göre dağılımları aşağıda Tablo 2'de gösterilmiştir. Çalışmaların büyük bir çoğunluğunun ABD'de yapıldığı (\%44.44), bunu Çin (\%9.52), Avustralya (\%6.35) ve İspanya'nın (\%4.76) takip ettiği görülmektedir. Diğer ülkeler arasında ikişer çalışmayla Brezilya, Fiji, Almanya, Pakistan, Tanzanya ve Türkiye, birer çalışmayla Kanada, Şili, Ekvador, İrlanda, Japonya, Malezya, Meksika, Filipinler ve Tayvan yer almaktadır.

Tablo 2. Erken Uyar Sistemleri Üz̧erine Yapılan Çalısmalarn Ülkelere Göre Dağgllmlar

\begin{tabular}{lcc}
\hline Çalışmanın Yapıldiğı Ülke & $\boldsymbol{f}$ & $\boldsymbol{\%}$ \\
\hline ABD & 28 & 44.44 \\
Diğer & 10 & 15.87 \\
Çin & 6 & 9.52 \\
Avustralya & 4 & 6.35 \\
İspanya & 3 & 4.76 \\
Almanya & 2 & 3.17 \\
Brezilya & 2 & 3.17 \\
Fiji & 2 & 3.17 \\
Pakistan & 2 & 3.17 \\
Tanzanya & 2 & 3.17 \\
Türkiye & 2 & 3.17 \\
\hline Toplam & $\mathbf{6 3}$ & $\mathbf{1 0 0 . 0 0}$ \\
\hline
\end{tabular}

Erken Uyarı Sistemleri Üzerine Yapılan Çalışmaların Türlerine Göre Dağılımları

Erken Uyarı Sistemleri üzerine yapılan çalısmaların türlerine göre dağllımları Tablo 3'te verilmiştir. Çalışmaların çoğu makale (\%53.97) türünde olmakla birlikte bunu bildiri (\%31.75) türünde olan çalışmalar takip etmektedir. Yapılan doktora (\%12.70) ve yüksek lisans (\%1.59) tez çalısmalarının sayısı diğer türlere nispeten az olsa da listede bunlara da yer verilmiştir.

Tablo 3. Erken Uyar Sistemleri Üžrine Yapılan Callşmalarn Türlerine Göre Dağıllmmlar

\begin{tabular}{lcc}
\hline Calışmanın Türü & $\boldsymbol{f}$ & $\boldsymbol{\%}$ \\
\hline Makale & 34 & 53.97 \\
Bildiri & 20 & 31.75 \\
Doktora Tezi & 8 & 12.70 \\
Yüksek Lisans Tezi & 1 & 1.59 \\
\hline Toplam & $\mathbf{6 3}$ & $\mathbf{1 0 0 . 0 0}$ \\
\hline
\end{tabular}

\section{Erken Uyarı Sistemleri Üzerine Yapılan Çalışmaların Yöntemlerine Göre Dağılımları}

Erken Uyarı Sistemleri üzerine yapılan araştırmaların tarandığı Google Akademik veri tabanından elde edilen çalışmaların yöntemlerine göre dağılımları Tablo 4'te verilmiştir. Çalışmaların neredeyse tamamına 
yakınını nicel çalışmalar (\%87.30) oluşturmaktadır. Bu çalışmaları \%11.11'lik bir pay ile derleme çalışmaları takip etmektedir. Çalışmaların bir tanesi de eylem araştırması olarak nitel çalışmalar (\%1.59) kategorisinde yer almıştır.

Tablo 4. Erken Uyarı Sistemleri Üzerine Yapılan Calssmalarn Yöntemlerine Göre Dağzllmları

\begin{tabular}{lll}
\hline Çalısmanın Yöntemi & $\boldsymbol{f}$ & $\boldsymbol{\%}$ \\
\hline Nicel & 55 & 87.30 \\
Derleme & 7 & 11.11 \\
Nitel & 1 & 1.59 \\
\hline Toplam & $\mathbf{6 3}$ & $\mathbf{1 0 0 . 0 0}$ \\
\hline
\end{tabular}

Erken Uyarı Sistemleri Üzerine Yapılan Deneysel Çalışmalarda Kullanılan Analiz Yöntemleri

Erken Uyarı Sistemleri üzerine yapılan deneysel çalısmalarda, öğrenme yönetim sistemi üzerindeki veriler kullanılarak elde edilen veriler üzerinde yapılan analizlerde kullanılan yöntemler frekans olarak Tablo 5’te verilmiştir. Birçok çalışmada bazı yöntemler bir arada kullanılmış ve en iyi sonucun hangisinde olduğu tespit edilmeye çalışılmışır. Bu yüzden tablodaki toplam sayı çalışma sayısından fazla olmaktadır.

Tablo 5. Erken Uyar Sistemleri Üzerine Yapulan Deneysel Çalssmalarda Kullamlan Analiz Yöntemleri

\begin{tabular}{ll}
\hline Analiz Yöntemleri & $\boldsymbol{f}$ \\
\hline Rastgele Orman (RF) & 13 \\
Tahmin Modelleme & 11 \\
Regresyon / Korelasyon & 10 \\
Destek Vektör Makineleri (SVM) & 9 \\
K-En Yakın Komşular (KNN) & 9 \\
Naive Bayes (NB) & 9 \\
Karar Ağaçları (DT) & 7 \\
Makine öğrenmesi & 7 \\
Lojistik regresyon (LR) & 6 \\
Erken Uyarı Sistemi & 5 \\
Yapay Sinir Ağları (YSA) & 5 \\
Çok Katmanlı Algılayıc1 (MLP) & 4 \\
Kümeleme & 4 \\
J48 & 4 \\
Öğrenme Analitikleri & 3 \\
\hline
\end{tabular}

Kullanılan analiz yöntemlerine bakıldığında en çok tercih edilen yöntemin Rastgele Orman Modeli olduğu görülmektedir. Çalışmalarda Tahmin Modelleme (Prediction Modeling) olarak bahsedilen yöntemin detayında ne yapıldığı belirtilmediği için genel olarak bu ifade kullanılmıştır. Çalışmalarda çeşitli regresyon ve korelasyon modellerinin uygulandığ da sık görülen yöntemler arasındadır. Bu çalışmaları sırasıyla Naive Bayes (NB), Destek Vektör Makineleri (SVM), K-En Yakın Komşular (KNN), Makine öğrenmesi, Karar Ağaçları (DT), Lojistik regresyon (LR), Erken Uyarı Sistemi, Yapay Sinir Ağları (YSA), Çok Katmanlı Algılayıc1 (MLP), Kümeleme yöntemleri, J48 ve Öğrenme Analitikleri takip etmektedir. Burada adı geçen Erken Uyarı Sistemleri, çalısmada öğrenme yönetim sistemine entegre edilen sistem olarak kabul edilmektedir, ancak detayında hangi yöntemin kullanıldığından bahsedilmemektedir.

\section{Erken Uyarı Sistemleri Üzerine Yapılan Deneysel Çalışmalarda Kullanılan Verilerin Alındığı Ortamlar}

Erken Uyarı Sistemleri üzerine yapılan deneysel çalışmalarda riskli öğrencileri tespit etmek için yapılacak analizlerde kullanılacak verilerin hangi ortamlardan alındığ Tablo 6'da verilmiştir. Yapılan çalışmaların yarısından fazlasında kullanılan verilerin sadece öğrenme yönetim sistemlerinden (ÖYS, \%61.82) alındığı görülmektedir. Diğer çalısmalarda ise öğrenme yönetim sisteminden alınan verilerin yanı sıra başka ortamlardan da veriler alınarak analizler yapılmıştır. Bu ortamların başında öğrenci bilgi sistemleri (ÖYS + ÖBS, \%21.82) gelmektedir. Çalışmaların sadece 2'sinde yalnızca öğrenci bilgi sisteminden (ÖBS, \%3.64) alınan veriler kullanılmıştır. 
Tablo 6. Erken Uyar Sistemleri Üzerine Yapılan Deneysel Callsmalarda Kullanılan Verilerin Alndiğ Ortamlar

\begin{tabular}{lcc}
\hline Veri Alinan Ortam & $\boldsymbol{f}$ & $\boldsymbol{\%}$ \\
\hline ÖYS & 34 & 61.82 \\
ÖYS + ÖBS & 12 & 21.82 \\
ÖYS + Anket & 3 & 5.45 \\
ÖYS + KAÇD & 2 & 3.64 \\
ÖBS & 2 & 3.64 \\
ÖYS + STEM & 1 & 1.82 \\
ÖYS + Yüz Yüze & 1 & 1.82 \\
\hline Genel Toplam & $\mathbf{5 5}$ & $\mathbf{1 0 0 . 0 0}$ \\
\hline
\end{tabular}

Erken Uyarı Sistemleri Üzerine Yapılan Deneysel Çalışmalarda Yapılan Analizlerde Kullanılan Veri Türleri

Google Akademik veri tabanı üzerinde yapılan tarama sonucu elde edilen Erken Uyarı Sistemleri üzerine yapılan deneysel çalışmalarda yapılan analizlerde kullanılan veriler Tablo 7'de verilmiştir. Yapılan nicel çalışmaların tamamında, analiz için kullanılan verilerin öğrenme yönetim sisteminden elde edilen kayıtlardan elde edildiği görülmektedir. Çalışmaların büyük bir kısmında (\%63.64) sadece sistem kayıtları kullanılmışken geri kalan kısmında (\%36.36) bu verilere öğrencilerin demografik verilerinin de eklendiği tespit edilmiştir.

Tablo 7. Erken Uyar Sistemleri Üzerine Yapılan Deneysel Callsmalarda Yapılan Analizlerde Kullanulan Veri Türleri

\begin{tabular}{lcc}
\hline Kullanılan Veri Türleri & $\boldsymbol{f}$ & $\boldsymbol{\%}$ \\
\hline Yalnız Sistem kayıtları & 35 & 63.64 \\
Sistem Kayıtlar1 + Demografik Veriler & 20 & 36.36 \\
\hline Genel Toplam & $\mathbf{5 5}$ & $\mathbf{1 0 0 . 0 0}$ \\
\hline
\end{tabular}

\section{Tartışma, Sonuç ve Öneriler}

Google Akademik arama motorunda yapılan tarama sonucu çalışma kapsamına alınan 63 çalışmanın; yapıldığı yıl, yapıllı̆̆ı ülke, yayın türü, araştırma yöntemi, çalışmalarda kullanılan analiz yöntemi, analizlerde kullanılan verilerin alındığı ortam ve kullanılan veri türü açısından incelenmiş ve aşağıdaki sonuçlara ulaşılmıştır.

Eğitim alanında Erken Uyarı Sistemleri üzerine yapılan çalışmaların 2014 yılından sonra başladığı sonucuna varılmışıır. 2018 ve 2019 yılında yapılan çalışmaların sayısının önceki yıllara göre iki katına çıktığ1 göz önüne alındığında gelecek birkaç yılda bu sayıların daha da artacağ1 tahmin edilmektedir. Özellikle uzaktan eğitimin yaygınlaşması ve veri madenciliği çalışmalarının da giderek artması bu öğrenme yönetim sistemine kolayca entegre edilebilen Erken Uyarı Sistemleri ile rahatça yapilabilmektedir.

Erken Uyarı Sistemleri üzerine yapılan çalışmaların ülkelere göre dağılımları incelendiğginde ABD'nin başı çektiği görülmektedir. ABD'de yapılan öğrenme analitikleri ve veri madenciliği çalışmalarının yaygın olması neticesinde Erken Uyarı Sistemleri üzerine yapılacak çalışmaların da bu gelişmelerden olumlu yönde etkilendiğini söylemek mümkündür. Yapılan bir araştırmanın sonucunda (Mduma, Kalegele ve Machuve, 2019, s. 1) eğitimde kullanılan makine öğrenmesi tekniklerini gelişmiş ülkeler önemsediği, gelişmekte olan ülkelerin ise bu tekniklere yeterince önem vermediği ortaya koyulmuştur. Türkiye ise 2019 yllinda yapılan iki çalışmayla bu listedeki yerini almışıtır.

Erken Uyarı Sistemleri üzerine yapılan çalısmaların türlerine göre dağılımları incelendiğinde, çalısmalarda çoğunlukla makale türü araştırmaların ve devamında bildiri türü araştırmaların tercih edildiğgi görülmektedir. Sayıları az da olsa konu ile ilgili lisansüstü çalışmalara da rastlanmıştır. Lisansüstü çalışmalar içerisinde doktora çalsşmalarının yüksek lisans çalışmalarına göre daha fazla tercih edildiği görülmektedir. Uzaktan eğitimin yaygınlaşmasıyla Erken Uyarı Sistemleri üzerine her türden çalışmanın yapılmasının mümkün olabileceği düşünülmektedir.

Erken Uyarı Sistemleri üzerine yapılan çalısmaların yöntemlerine göre dağılımları incelendiğinde nicel araştırmaların sıklıkla tercih edildiği görülmektedir. Erken Uyarı Sistemleri, öğrenme yönetim sistemi verileri üzerinde yapılan veri madenciliği temeline dayandığı için bu çalışmaların nicel yöntemlerle 
yapılmasının ve elde edilen büyük verilerin yine bu yöntemlerle analiz edilmesinin beklenen bir sonuç olduğu düşünülmektedir. Görüşme veya gözlem yoluyla toplanan veriler makine öğrenmesi çalışmaları için nicel olarak yeterli sayıya ulaşmadığından veya makine öğrenmesi çalışmalarında gerekli sonucu elde edebilmek adına çok fazla görüşme veya gözlem yoluyla veri toplamak gerekeceğinden bu yöntemlerin tercih edilmiyor olabileceği düşünülmektedir.

Erken Uyarı Sistemleri üzerine yapılan deneysel çalışmalarda riskli öğrencileri tespit etmek için çok sayıda analiz yönetiminin kullanıldığı görülmektedir. Literatürde farklı modellerin karşılaştırıldığı çalışmalara rastlamak mümkündür (Akçapınar vd., 2019; Baneres, Rodriguez-Gonzalez ve Serra, 2019; Hung, Shelton, Yang ve Du, 2019; Sandoval vd., 2018; Marbouti vd., 2016; Dewan vd., 2015). Bu yöntemlerden hangisinin en iyi yöntem olduğu konusunda eldeki verilere dayalı olarak kesin bir şey söylemek mümkün değildir. Ancak çalışmalarda tercih edilme sıklığı açısından en çok rastlanan modelin Rastgele Orman (Random Forest) modeli olduğu görülmektedir. Diğer modellerin nispeten daha az tercih edilmeleri bu modellerin daha az işe yaradığı anlamına gelmemelidir. Bir modelin tahmin gücünün yüksek olması seçilen verilerin türlerine bağlı olarak değişmektedir. Aly ve Hasan (2019, s. 205), yapmış oldukları çalışmada riskli öğrencileri tahmin etmek için 7 farklı modeli karşılaştırmışlardır. Her bir modelin risk türlerinden birini tahmin etmede diğerine göre daha iyi sonuç verdiği söylenmektedir. Her bir modelin diğerlerine karşı üstün olduğu sonuçların yanı sıra çalışmanın sonuç kısmında her türlü tahmin işinde kullanılabilecek en iyi modelin hangisi olduğu net bir șekilde ortaya konulamamıştır. Yapmış olduğu farklı denemeler sonucunda tatmin edici bir başarı elde edemeyen Mi (2019, s. 831) de henüz doğrulanmış bir modelin olmadığı görüşünü ileri sürmektedir. Bu açıdan bakıldığında bu alanda yapılacak deneysel çalışmaların sayısının arttırılmasının gerektiği söylenebilir. Analiz yöntemlerinin teker teker denendiği veya birkaçının bir arada kullanılarak karşılaştırmalarının yapılacağı türden çalışmalar uzaktan eğitim veren kurumlara hizmet edecektir.

Erken Uyarı Sistemleri üzerine yapılan deneysel çalışmalarda kullanılan verilerin alındığı ortamlar incelendiğinde bütün çalışmalarda öğrenme yönetim sistemleri (ÖYS) kullanılmış, \%40’a yakın orandaki çalışmalarda ise bu sistemlere ek olarak öğrenci bilgi sistemi ve Kitlesel Açı Çevrimiçi Dersler (KAÇD) gibi sistemlerden alınan verilerle desteklendiği görülmüştür. Günümüzde özellikle salgından dolayı oldukça yaygın hale gelen uzaktan öğretimin ve örgün öğretimlerin sınıf dışı çevrimiçi etkinliklerle desteklendiği harmanlanmış öğrenme etkinlikleri sayesinde öğrencilerin davranışları hakkında toplanacak veriler için en iyi kaynağı başta öğrenme yönetim sistemleri ve devamında öğrenci bilgi sistemleri oluşturmaktadır. Bazı araştırmalarda öğrencilerin kişilik ve aile geçmişi gibi verilerin analiz için kullanıldığına rastlanılsa da hala en çok tercih edilen veri kaynağının ÖYS olduğu (Yuxiang, 2019, s. 262), ÖYS üzerinde tutulan izleme verilerinin öğrenme analitikleri için temel veri kaynağı olduğu (Tempelaar, Rienties ve Giesbers, 2015, s. 158) söylenmektedir. Uzaktan eğitim veren her kurum bu anlamda öğrenci davranışlarını takip altına alabilir ve riskli öğrencileri tespit etmek üzere kullanabilir.

Erken Uyarı Sistemleri üzerine yapılan deneysel çalışmalarda yapılan analizlerde kullanılan verilerin türlerine bakıldığında, öğrenme yönetim sisteminden elde edilen sistem kayıtlarının ve öğrenci bilgi sistemi gibi diğer sistemlerden de demografik verilerin alındığı görülmektedir. Erken Uyarı Sistemleri üzerinde yapılan deneysel çalışmalarda öğrenme yönetim sisteminde sunulan ders materyallerine yapılan tıklama sayıları, materyallerle geçirilen süreler bu çalışmalarda en çok rastlanan bağımsız değişkenler olarak karşımıza çıkmaktadır. Genel olarak bir öğrenme yönetim sisteminin sağladığı öğrenci davranışlarını kaydetme imkânı ile elde edilen bütün kayıtların tamamı genellikle bu analizlerde kullanılmaktadır. Böylece elde edilen ilişkisel formüllerin daha gerçekçi olacağı düşünülmektedir.

Sonuç olarak, Erken Uyarı Sistemleri üzerine yapılan çalışmalar incelendiğinde eğitim ile ilgili olanların 2014 yılından sonra görülmeye başladığı ve 2018 yılında hızla artışa geçtĭgi, bu çalısmaların çoğunlukla ABD'de yapıldığı görülmüştür. Çalışmaların çoğunlukla makale ve bildiri türünde olduğu, çalışmalarda sıklıkla nicel yöntemlerin tercih edildiği belirlenmiştir. Yapılan deneysel çalışmalarda öğrenme yönetim sisteminden alınan sistem kayıtlarından elde edilen veriler üzerinde yapılan çeşitli veri madenciliği analizleri ile incelendiği tespit edilmiştir.

\section{Etik Beyan}

"Eğitimde Kullamlan Erken Uyar Sistemleri Konusunda Yapılmuş Çalıs̆maların İncelenmesi" başlıklı çalışmanın yazım sürecinde bilimsel kurallara, etik ve alıntı kurallarına uyulmuş; toplanan veriler üzerinde herhangi bir tahrifat yapılmamış ve bu çalısma herhangi başka bir akademik yayın ortamına değerlendirme için 
gönderilmemiştir. $\mathrm{Bu}$ araştırmada doküman incelemesi yapıldığından etik kurul kararı zorunluluğu bulunmamaktadır.

\section{Kaynakça}

Akçapınar, G., Altun, A. ve Aşkar, P. (2019). Using learning analytics to develop early-warning system for at-risk students. International Journal of Educational Technology in Higher Education, 16(40), 1-20. doi: 10.1186/s41239-0190172-z

Akçapınar, G., Hasnine, M., Majumdar, R., Flanagan, B. ve Ogata, H. (2019). Developing an early-warning system for spotting at-risk students by using eBook interaction logs. Smart Learning Environments, 6(4). doi: 10.1186/s40561-019-0083-4

Aly, M. ve Hasan, M. (2019). Improving STEM performance by leveraging machine learning models. Int'l Conf. Frontiers in Education: CS and CE (FECS'19), (pp. 205-211).

Arnold, K. (2017). The effects of educational technology usage profiles and legally protected bio-demographic data on behaviorally based predictive student success models in learning analytics: An exploratory study (Doctoral Dissertation). Purdue University.

Baneres, D., Rodriguez-Gonzalez, M. E. ve Serra, M. (2019). An early feedback prediction system for learners at-risk within a first-year higher education course. IEEE Transactions on Learning Technologies, 12(2), 249-263. doi: 10.1109/TLT.2019.2912167

Brown, M., DeMonbrun, R. ve Teasley, S. (2018). Taken together: conceptualizing students' concurrent course enrollment across the post-secondary curriculum using temporal analytics. The Journal of Learning Analytics, 5(3), 60-72. doi: 10.18608/jla.2018.53.5

Büyüköztürk, Ş., Kılıç Çakmak, E., Akgün, Ö. E., Karadeniz, Ş. ve Demirel, F. (2009). Bilimsel araştirma yöntemleri. Ankara: Pegem Akademi.

Cohen, L., Manion, L. ve Morrison, K. (2007). Research methods in education. Taylor \& Francis e-Library.

DeGraff, J., DeGraff, N. ve Romesburg, H. (2013). Literature searches with Google Scholar: Knowing what you are and are not getting. GSA Today, 23(10), 44-45. doi: 10.1130/GSAT175GW.1

Dewan, M., Lin, F., Wen, D. ve Kinshuk. (2015). Predicting dropout-prone students in e-learning education system. UIC-ATC-ScalCom-CBDCom-IoP 2015, (pp. 1735-1740). Beijing, China. doi: 10.1109/UIC-ATC-ScalComCBDCom-IoP.2015.315

Elbadrawy, A., Polyzou, A., Ren, Z., Sweeney, M., Karypis, G. ve Rangwala, H. (2016). Predicting Student Performance Using Personalized Analytics. Computer, 49(4), 61-69. doi: 10.1109/MC.2016.119

He, L., Levine, R., Bohonak, A., Fan, J. ve Stronach, J. (2018). Predictive Analytics Machinery for STEM Student Success Studies. Applied Artificial Intelligence, 32(4), 361-387. doi: 10.1080/08839514.2018.1483121

Hill, F., Fulcher, D., Sie, R. ve de Laat, M. (2018). Balancing Accuracy and Transparency in Early Alert Identification of Students at Risk. 2018 IEEE International Conference on Teaching, Assessment, and Learning for Engineering (TALE), (pp. 1125-1128). Wollongong, NSW, Australia. doi: 10.1109/TALE.2018.8615370

Howard, E., Meehan, M. ve Parnell, A. (2018). Contrasting prediction methods for early warning systems at undergraduate level. The Internet and Higher Education, 37, 66-75. doi: 10.1016/j.iheduc.2018.02.001

Hung, J.-L., Shelton, B., Yang, J. ve Du, X. (2019). Improving predictive modeling for at-risk student identification: A multistage approach. IEEE Transactions on Learning Technologies, 12(2), 148-157. doi: 10.1109/TLT.2019.2911072

Hung, J. L., Wang, M., Wang, S., Abdelrasoul, M., Li, Y. ve He, W. (2017). Identifying At-Risk Students for Early Interventions-A Time-Series Clustering Approach. IEEE Transactions on Emerging Topics in Computing, 5(1), 4555. doi: 10.1109/TETC.2015.2504239

Hussain, M., Zhu, W., Zhang, W., Abidi, S. ve Ali, S. (2018). Using machine learning to predict student difficulties from learning session data. Artificial Intelligence Review. doi: 10.1007/s10462-018-9620-8

Jokhan, A., Sharma, B. ve Singh, S. (2018). Early warning system as a predictor for student performance in higher education blended courses. Studies in Higher Education. doi:10.1080/03075079.2018.1466872

Kotsiantis, S. (2012). Use of machine learning techniques for educational proposes: a decision support system for forecasting students' grades. Artificial Intelligence Review, 37(4), 331-344. doi: 10.1007/s10462-011-9234-x

Macfadyen, L. ve Dawson, S. (2010). Mining LMS data to develop an "early warning system" for educators: A proof of concept. Computers \& Education, 54(2), 588-599. doi: 10.1016/j.compedu.2009.09.008

Marbouti, F., Diefes-Dux, H. ve Madhavan, K. (2015). Predictive modeling for identifying at-risk students using course performance data. The 6th Research in Engineering Education Symposium. Ireland, Dublin.

Marbouti, F., Diefes-Dux, H., \& Madhavan, K. (2016). Models for early prediction of at-risk students in a course using standards-based grading. Computers \& Education, 103, 1-15. doi: 10.1016/j.compedu.2016.09.005

Mduma, N., Kalegele, K. ve Machuve, D. (2019). A Survey of Machine Learning Approaches and Techniques for Student Dropout Prediction. Data Science Journal, 18(14), 1-10. doi: 10.5334/dsj-2019-014

Mi, C. (2019). Student Performance Early Warning based on Data Mining. International Journal of Performability Engineering, 15(3), 822-833. 
Samson, P., Czarnik, A. ve Gross, M. (2017). Relationships Between Digital Measures of Student Engagement and Exam Scores: Is the LMS Enough? 7th International Learning Analytics \& Knowledge Conference (LAK17): Practitioner Track, (pp. 106-117). Vancouver, Canada.

Sandoval, A., Gonzalez, C., Alarcon, R., Pichara, K. ve Montenegro, M. (2018). Centralized student performance prediction in large courses based on lowcost variables in an institutional context. The Internet and Higher Education, 37, 76-89. doi: 10.1016/j.iheduc.2018.02.002

Sclater, N., Peasgood, A., \& Mullan, J. (2016). Learning analytics in higher education: A review of UK and international practice. London: Jisc.

Sezer, A. (1994). Türkiyede bitki hastahklarmm savaşımında kullanılan ön tahmin ve erken uyarn sistemleri (Yüksek Lisans Tezi). Ankara Üniversitesi / Fen Bilimleri Enstitüsü.

Stapel, M., Zheng, Z. ve Pinkwart, N. (2016). An Ensemble Method to Predict Student Performance in an Online Math Learning Environment. 9th International Conference on Educational Data Mining, (pp. 231-238). Raleigh, NC.

Tempelaar, D., Rienties, B. ve Giesbers, B. (2015). In search for the most informative data for feedback generation: Learning Analytics in a data-rich context. Computers in Human Behavior, 47, 157-167. doi: 10.1016/j.chb.2014.05.038

Waddington, R., Nam, S., Lonn, S. ve Teasley, S. (2016). Improving early warning systems with categorized course resource usage. Journal of Learning Analytics, 3(3), 263-290. doi: 10.18608/jla.2016.33.13

Yıldırım, A., \& Şimşek, H. (2005). Sosyal bilimlerde nitel araştırma yöntemleri (5. Baskı). Ankara: Seçkin Yayıncılık.

Yuxiang, W. (2019). Academic Supervision and Risk Assessment Based on Moodle LMS Data. 2019 International Conference on Robots \& Intelligent System (ICRIS). Warsaw, Poland. doi: 10.1109/ICRIS.2019.00075

\section{EXTENDED ABSTRACT}

Early Warning Systems (EWS) are one of the tools used by educators to monitor student progress and identify students at risk of failing or leaving a course or program (Jokhan, Sharma, \& Singh, 2018). Predicting students at risk requires data from students who did not complete the program or who dropped out after certain behavior in the system. It is possible to make future predictions by developing artificial intelligence-based systems that are trained using this data (Kotsiantis, 2012). With the spread of distance education using online environments, student behaviors are recorded by Learning Management Systems (LMS) and EWS can be developed using this data (Macfadyen \& Dawson, 2010).

The following methods are mostly encountered in EWS developed using data from LMS:

- Random Forest Model (Elbadrawy et al. 2016; He, Levine, Bohonak, Fan, \& Stronach, 2018; Hill, Fulcher, Sie, \& de Laat, 2018; Samson, Czarnik, \& Gross, 2017; Sandoval, Gonzalez, Alarcon, Pichara, \& Montenegro, 2018)

- Logistic Regression Model (Arnold, 2017; Hill et al. 2018; Hussain, Zhu, Zhang, Abidi, \& Ali, 2018; Waddington, Nam, Lonn, \& Teasley, 2016)

- Cluster Analysis (Brown, DeMonbrun, \& Teasley, 2018; Hung, et al., 2017; Stapel, Zheng, \& Pinkwart, 2016)

- Support Vector Machines (Dewan, Lin, Wen, \& Kinshuk, 2015; Hussain et al. 2018; Marbouti, Diefes-Dux, \& Madhavan, 2016)

- K-Nearest Neighbor Analysis (Dewan et al. 2015; Marbouti, Diefes-Dux, \& Madhavan, 2015; Marbouti et al. 2016)

This study aimed to reveal the current situation by examining the studies on EWS used in education. For this purpose, the questions of this paper are as follows.:

1. What is the distribution of studies on EWS by years?

2. What is the distribution of studies on EWS by country?

3. What is the distribution of studies on EWS according to their types?

4. What is the distribution of the studies on EWS according to their methods?

5. Which analysis methods have been used in experimental studies on EWS?

6. From which media were the data used in experimental studies on EWS taken?

7. What types of data have been used for the analysis of the experimental studies on EWS?

The document analysis method, one of the qualitative research methods, was used in this study, in which studies on EWS were examined. EWS studies were analyzed in terms of the year, the country in which they were conducted, the type of publication, the research method, the method of analysis used in the studies, the environment from which the data were used in the analysis, and the type of data used. The Google Scholar search engine was used to find relevant studies. It has been tried to reach the relevant studies by using the keywords "early warning systems" and "LMS" together in the Google Academic 
search engine. The search made on the Google Scholar search engine reached 512 records. After the excluded studies, 63 studies were examined and answers were sought for research questions. The documents obtained were analyzed by the content analysis method.

As a result, when the studies on EWS were examined, it has seen that those related to education started to be seen after 2014 and started to increase rapidly in 2018, and these studies were mostly carried out in the USA. It was found that research was conducted primarily in the form of articles and conference reports, and quantitative methods were often preferred in research. In the experimental studies, it was determined that the data obtained from the system records taken from the LMS were examined by various data mining methods.

It has been observed that studies on EWS in the field of education started after 2014. Considering that the number of studies conducted in 2018 and 2019 has doubled compared to previous years, it is estimated that these numbers will increase in the next few years.

It was seen that most of the studies on EWS are done in the USA. As a result of the widespread use of learning analytics and data mining in the USA, it is possible to say that studies on EWS have also been positively affected by these developments.

It was defined that the studies on the EWS are mostly article-type researches, followed by conference paper-type studies. With the widespread use of distance education, it is thought that it will be possible to carry out all kinds of studies on EWS.

It can be seen that quantitative research is often favored over EWS research. Since EWS is based on data mining on LMS data, it is believed that conducting these studies using quantitative methods and analyzing the resulting big data using these methods is the expected result.

In experimental studies on EWS, it was determined that the most common model in terms of preference is the Random Forest model. In all of the studies, LMS was used as a data source, and in some studies, it was seen that these systems were supported by data from systems such as student information systems and Massive Open Online Courses (MOOC). Every institution providing distance education can monitor student behavior in this sense and use it to identify risky students.

In experimental studies on EWS, it is seen that the system records obtained from LMS and demographic data from other systems such as student information systems are also obtained. In general, all the records obtained by the opportunity to record student behaviors provided by a learning management system are generally used in these analyses. 